\title{
Bufalin suppresses the proliferation and metastasis of renal cell carcinoma by inhibiting the PI3K/Akt/mTOR signaling pathway
}

\author{
JINLIN XIE ${ }^{1 *}$, WENFENG LIN $^{1 *}$, LINGLONG HUANG $^{1}$, NAIJIN XU ${ }^{2}$, ABAI XU ${ }^{1}$, \\ BINSHEN CHEN ${ }^{1}$, MASAMI WATANABE ${ }^{2}$, CHUNXIAO LIU $^{1}$ and PENG HUANG ${ }^{1-3}$ \\ ${ }^{1}$ Department of Urology, Zhujiang Hospital, Southern Medical University, Guangzhou, Guangdong 510282, P.R. China; \\ ${ }^{2}$ Department of Urology, Okayama University Graduate School of Medicine, Dentistry and Pharmaceutical Sciences; \\ ${ }^{3}$ Okayama Medical Innovation Center, Okayama University, Okayama 700-8558, Japan
}

Received November 15, 2017; Accepted July 3, 2018

DOI: $10.3892 / \mathrm{ol} .2018 .9111$

\begin{abstract}
Bufalin, one of the active ingredients of the Chinese drug Chan su, exhibits significant antitumor activity against various cancer types. However, the role of bufalin in renal cell carcinoma (RCC) remains unclear. In the present study, it was demonstrated that bufalin inhibited cell proliferation, blocked the cell cycle in the $\mathrm{G} 2 / \mathrm{M}$ phase, and reduced the metastasis of human RCC ACHN cells via the upregulation of $\mathrm{p} 21^{\text {waf/cip }}$ and E-cadherin and the downregulation of cyclin dependent kinase 1, cyclin B1, N-cadherin, and hypoxia-inducible factor-1 $\alpha$ (HIF-1 $\alpha)$. Further mechanistic study revealed that bufalin reduced the expression of phosphorylated (phospho)-Akt and phospho-mammalian target of rapamycin (mTOR). Moreover, HIF-1 $\alpha$ expression may be regulated through the inhibition of the phosphoinositide 3-kinase $(\mathrm{PI} 3 \mathrm{~K}) /$ protein kinase $\mathrm{B}(\mathrm{Akt}) / \mathrm{mTOR}$ signaling pathway. Thus, the present results suggest that bufalin induces cell cycle arrest and suppresses metastasis; this process may be associated with the PI3K/Akt/mTOR signaling pathway. Accordingly, it is suggested that bufalin is a therapeutic agent for RCC.
\end{abstract}

Correspondence to: Professor Peng Huang or Professor Chunxiao Liu, Department of Urology, Zhujiang Hospital, Southern Medical University, 253 Gongye Avenue, Guangzhou, Guangdong 510280, P.R. China

E-mail: huangpeng509@gmail.com

E-mail: liuchx888@hotmail.com

*Contributed equally

Abbreviations: ANOVA, analysis of variance; DAPI, 4,6-diamidino-2-pheylindole; DMSO, dimethyl sulfoxide; EMT, epithelial-to-mesenchymal transition; PBS, phosphate-buffered saline; PI, propidium iodide; RCC, renal cell carcinoma; SD, standard deviation

Key words: bufalin, renal cell carcinoma, cycle arrest, metastasis, p-Akt

\section{Introduction}

Renal cell carcinoma (RCC) is one of the most prevalent cancers, accounting for $2 \%$ of adult malignancies (1); its incidence is steadily rising by approximately $2 \%$ per year (2). Although the rate of early diagnosis of RCC has increased with the development of diagnostic techniques in recent years, up to $30 \%$ of patients are diagnosed with metastasized RCC, and one-third of local RCCs eventually recur and metastasize after surgical resection $(3,4)$. Currently, surgery still plays a dominant role in the first-line treatment of RCC. However, metastatic RCC ( $\mathrm{mRCC}$ ) cannot be treated with radical surgery and is generally not sensitive to chemotherapy or radiotherapy. Combined treatment (cytoreductive nephrectomy, cytokine therapy, and targeted therapeutic agent treatment) may prolong survival. Despite the improvements in most treatment modalities, mRCC patients still have extremely poor outcomes, with an overall median survival of $<1$ year $(4,5)$. Hence, there is an urgent need to enhance our understanding of the biological signaling pathways involved in RCC and to identify novel therapeutic agents.

The phosphoinositide 3-kinase (PI3K)/protein kinase B (Akt)/mammalian target of rapamycin (mTOR)-signaling pathway plays a pivotal role in cell survival and growth via its effect on multiple signaling pathways and is frequently disturbed in the majority of human cancers $(6,7)$. Recent researches have revealed that the activation of Akt requires the phosphorylation of Thr308 in Akt1 and phosphorylation within the carboxy terminus at Ser473 $(8,9)$. Inactivated Akt protein promotes cell survival via the phosphorylation and inactivation of several targets, including Caspase- 3 and caspase-9, and regulates cell cycle progression through a reduction in the expression of cyclin-dependent kinase inhibitors $\mathrm{p} 21^{\mathrm{waf} / \mathrm{cip} 1}$ and $\mathrm{p} 27$ (10). Indeed, studies have shown that $\mathrm{PI} 3 \mathrm{~K} / \mathrm{Akt} / \mathrm{mTOR}$ can regulate hypoxia-inducible factor- $1 \alpha$ (HIF-1 $\alpha)(11)$, a critical mediator of the physiological response to hypoxia, and its dysregulation can promote tumor angiogenesis and metastasis (12).

mTOR kinase forms two distinct kinase complexes, mTORC1 and mTORC2. mTORC1 controls cellular growth and metabolic processes by inactivating P70S6K and 4EBP1, and mTORC2 controls cellular survival through 
the phosphorylation of Akt at Ser473 (13). Considering that enhanced activity of the PI3K/Akt/mTOR pathway is frequently observed in malignant cells, the inhibition of mTOR is an attractive strategy to treat cancer. Currently, there are two methods of targeted therapeutic agents for mRCC: Tyrosine kinase inhibitors targeting tumor angiogenesis and mTOR inhibitors. However, the emergence of drug resistance may ultimately limit the utility of mTOR inhibitors (14).

Bufalin (Fig. 1A), an active component of the traditional Chinese drug Chan Su $(15,16)$, has been reported to have anti-tumor effects on various types of cancers, including breast, lung, liver, prostate, and cervical cancer (17-21). These studies have suggested that bufalin is a potential therapeutic agent for combined chemotherapy. However, the effect of bufalin on RCC has not yet been thoroughly evaluated. In this study, we sought to illustrate the anti-tumor effects and potential basic mechanisms of bufalin in the human RCC ACHN cell line.

\section{Materials and methods}

Cell lines and chemicals. Human RCC ACHN cells were purchased from the Cell Bank of the Chinese Academy of Sciences (Shanghai, China) and cultured at $37^{\circ} \mathrm{C}$ in $5 \% \mathrm{CO}_{2}$ in RPMI-1640 medium supplemented with $10 \%$ fetal bovine serum (Gibco; Thermo Fisher Scientific, Inc., Waltham, MA, USA) and antibiotics (100 $\mu \mathrm{g} / \mathrm{ml}$ of streptomycin and $100 \mathrm{U} / \mathrm{ml}$ of penicillin). Bufalin, with a purity of up to $98 \%$, was purchased from the Shanghai Yuanye Biological Technology Company (Shanghai, China); dissolved in dimethyl sulfoxide (DMSO) to a concentration of $50 \mu \mathrm{mol} / 1$; and stored at $-20^{\circ} \mathrm{C}$. The anti-cyclin B1 (1:1,000 dilution, no. 12231), anti-cdc2, also known as anti-CDK1 (1:1,000 dilution, no. 28439), anti-p2 $^{\text {waf/cipl }}(1: 1,000$ dilution, no. 2947), anti-E-cadherin (1:1,000 dilution, no. 3195), anti-N-cadherin (1:1,000 dilution, no. 13116), anti-Akt (1:1,000 dilution, no. 4691), anti-p-Akt (Ser473) (1:1,000 dilution, no. 4060) anti-mTOR (1:1,000 dilution, no. 2983), and anti-p-mTOR (Ser2448) antibodies (1:1,000 dilution, no. 5536) were purchased from Cell Signaling Technology, Inc. (Danvers, MA, USA). The antibodies against GAPDH (1:1,000 dilution, no. WL01114), HIF-1 $\alpha$ (1:700 dilution, no. WL01607), and PI3K (1:700 dilution, WL01169) were obtained from Wanlei Biological Technology Co. (Shenyang, China).

Cell viability assay. ACHN cell viability was detected using the Cell Counting Kit-8 assay (CCK-8; Dojindo Laboratories, Kumamoto, Japan). Briefly, ACHN cells $\left(5 \times 10^{3}\right.$ per well) were seeded in 96-well plates and cultured for $24 \mathrm{~h}$. Then, the cells were treated with the designated concentrations of bufalin for $12,24,48$, or $72 \mathrm{~h}$. After incubation, $10 \mu \mathrm{l}$ of CCK-8 solution was added to each well and incubated at $37^{\circ} \mathrm{C}$ in $5 \% \mathrm{CO}_{2}$ for an additional $1 \mathrm{~h}$. The optical density value of absorbance at $450 \mathrm{~nm}$ was detected using a microplate reader (ELx808; BioTek Instruments, Inc., Winooski, VT, USA). The experiments were conducted three times.

Colony-forming assay. A total of $5 \times 10^{2}$ cells were seeded in 6-well plates at single-cell density and treated with different concentrations of bufalin for $24 \mathrm{~h}$. Then, the complete medium was added to allow cell growth for 10 days at $37^{\circ} \mathrm{C}$ in $5 \% \mathrm{CO}_{2}$.
Colonies with $>50$ cells were photographed and counted after staining with crystal violet (Beijing Solarbio Science \& Technology Co., Ltd., Beijing, China).

Cell-cycle and apoptosis analyses. ACHN cells were treated with different concentrations of bufalin for $24 \mathrm{~h}$ and then harvested, washed twice with phosphate-buffered saline (PBS), and re-suspended in $200 \mu 1$ of PBS. The cells were fixed in $2 \mathrm{ml}$ of ice-cold $70 \%$ ethanol at $4^{\circ} \mathrm{C}$ overnight. The precipitate was obtained by centrifugation and added to $450 \mu \mathrm{l}$ of propidium iodide (PI; Sigma-Aldrich; Merck KGaA, Darmstadt, Germany) and $50 \mu 1$ of RNase (MP Biomedicals, Solon, $\mathrm{OH}, \mathrm{USA}$ ) in a $37^{\circ} \mathrm{C}$ water bath for $15-20 \mathrm{~min}$ and then analyzed within $4 \mathrm{~h}$. Apoptosis analysis was performed similarly except that the cells were stained with $5 \mu \mathrm{l}$ of Annexin V (eBioscience; Thermo Fisher Scientific, Inc., Waltham, MA, USA) for $15 \mathrm{~min}$ in dark conditions at room temperature, and $10 \mu \mathrm{l}$ PI was added prior to immediate analysis. The cell status was detected by flow cytometry (BD FACSVerse, USA), and then the cell cycle data were analyzed using ModFit LT (for Windows, version 3.0) software; the apoptosis data were analyzed using BD FACSuite software. The results are expressed as the mean values from three independent determinations.

Wound-healing assay. ACHN cells were seeded in 6-well plates and grown to $80-90 \%$ confluence. A wound was scratched with a $200-\mu 1$ pipette tip and washed twice with PBS. Then, the cells were treated with various concentrations of serum-free medium containing bufalin for $24 \mathrm{~h}$. Wound closure was photographed at 0 and $24 \mathrm{~h}$ with an inverted microscope (Carl Zeiss AG, Oberkochen, Germany). The results are presented as the migration index, which is the ratio of the cell migration area at $24 \mathrm{~h}$ to the scratched area at $0 \mathrm{~h}$.

Cell migration and invasion assay. A cell migration assay, the Transwell assay, was performed. The chambers (BD Biosciences, Franklin Lakes, NJ, USA) with $8-\mu \mathrm{m}$ (pore size) polycarbonate filters were precoated with Matrigel BD Biosciences). ACHN cells were treated with bufalin at different concentrations for $12 \mathrm{~h}$; they were then harvested, washed with serum-free medium, re-suspended to a final concentration of $5 \times 10^{4}$ cells in $100 \mu 1$ serum-free medium, and placed in the upper chamber. The lower chamber contained $0.5 \mathrm{ml}$ of medium containing 20\% fetal bovine serum. Cells were allowed to invade at $37^{\circ} \mathrm{C}$ for $24 \mathrm{~h}$. Invaded cells were stained with crystal violet and manually counted under a microscope. The cell invasion assay was performed similarly, except that $50 \mu \mathrm{l}$ of Matrigel diluted to a concentration of $1: 8$ with serum-free medium was added to each well for $2 \mathrm{~h}$ at $37^{\circ} \mathrm{C}$ before the cells were seeded into the upper chamber.

Western blot analysis. The treated cells were washed twice with cold PBS and lysed with RIPA lysis buffer (ComWin Biotech, Beijing, China) containing $1 \%$ phosphatase inhibitor (ComWin Biotech) and 1\% protease inhibitor (ComWin Biotech). The total protein concentration was determined by the BCA protein assay kit (Beyotime Institute of Biotechnology, Shanghai, China). Equal amounts (30 $\mu \mathrm{g}$ per load) of protein samples were electrophoresed using sodium 

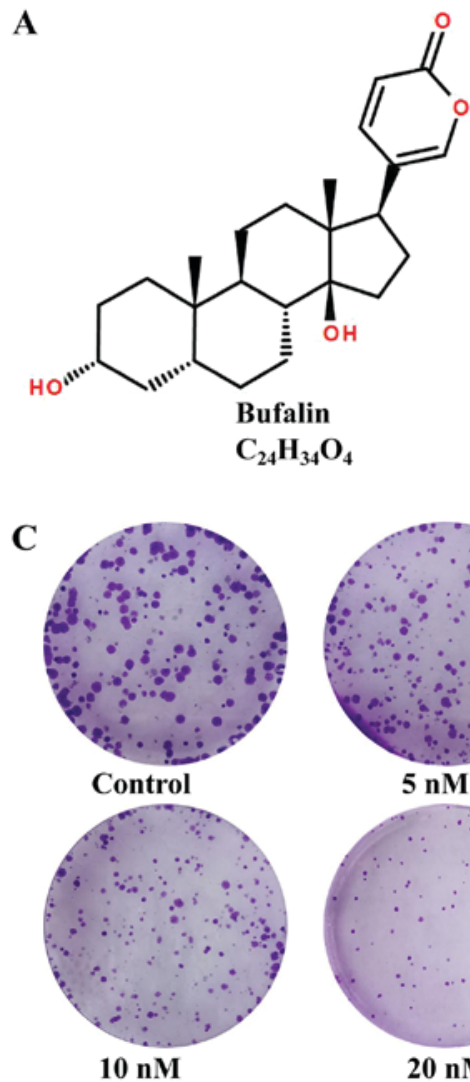
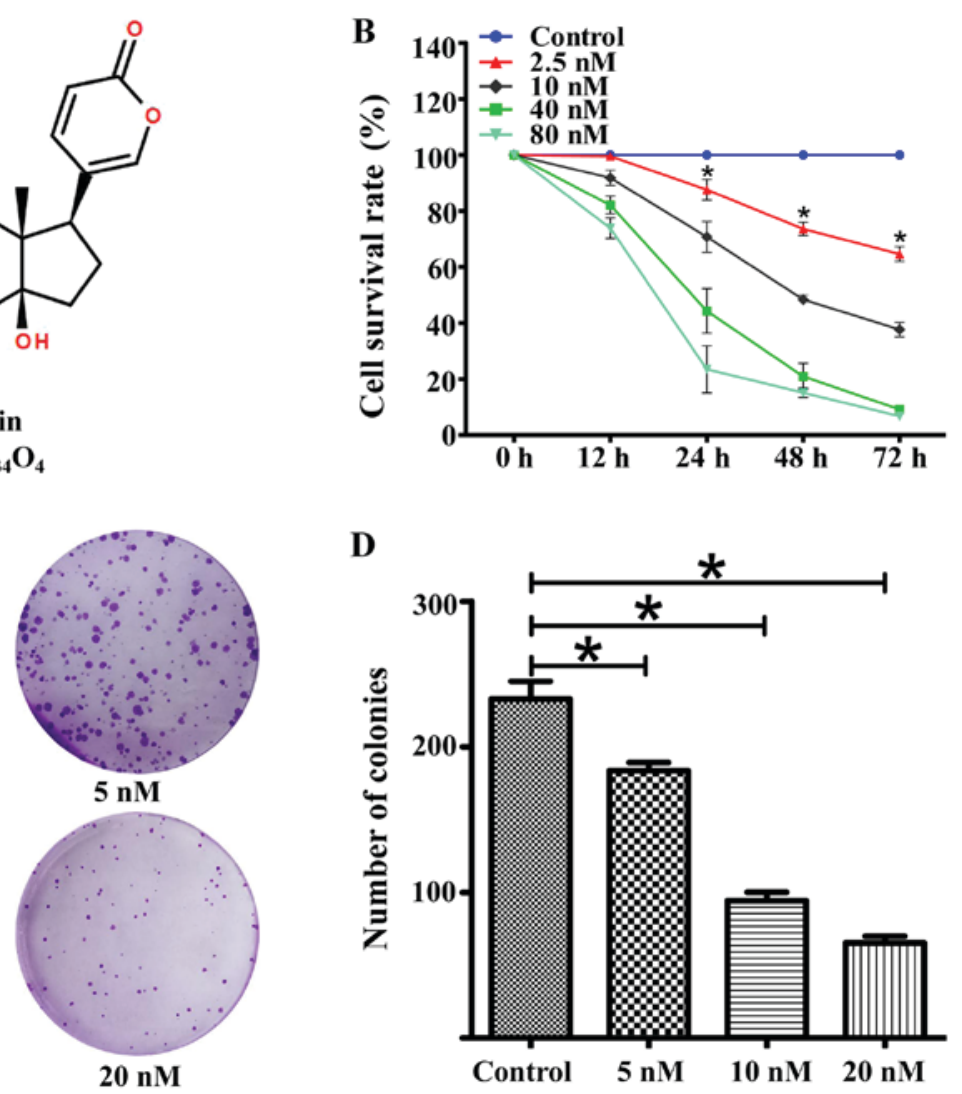

Figure 1. Bufalin inhibited ACHN cell proliferation and reduced the colony-forming ability of ACHN cells. (A) Chemical structure of bufalin. (B) Bufalin inhibited the proliferation of ACHN cells. Cell viability determined by the CCK-8 assay. Data are presented as mean $\pm \operatorname{SD}\left({ }^{*} \mathrm{P}<0.05\right)$. (C) Representative images of cell colonies after treatment with various concentrations of bufalin for 10 days. (D) Colony formation rate significantly reduced after treatment with bufalin for 10 days. Data are presented as mean \pm SD ("P<0.05). SD, standard deviation; CCK-8, Cell Counting Kit- 8 .

dodecyl sulfate-polyacrylamide gel electrophoresis and were transferred onto polyvinylidene fluoride membranes (EMD Millipore, Billerica, MA, USA). The blots were blocked in $5 \%$ non-fat milk for $1 \mathrm{~h}$, and the membranes were washed and incubated with the primary antibody overnight at $4^{\circ} \mathrm{C}$, after shaking. After washing with TBS-T, the membranes were incubated with secondary antibody at room temperature for $1 \mathrm{~h}$. The proteins were visualized using an ECL Kit (EMD Millipore), and signal detection was performed in a Bio-Rad Universal Hood 2 Electrophoresis Imaging Cabinet.

Immunofluorescence staining assay. ACHN cells treated with or without bufalin for $24 \mathrm{~h}$ were fixed with $4 \%$ paraformaldehyde for $15 \mathrm{~min}$ at room temperature. After being washed with PBS three times, the cells were permeabilized with $0.5 \%$ Triton X-100 for $30 \mathrm{~min}$, followed by another three washes with PBS. The cells were blocked in goat serum for $1 \mathrm{~h}$ and then incubated with various primary antibodies overnight. The next day, after being washed with PBS three times, the cells were incubated with the appropriate secondary antibody (Thermo Fisher Scientific, Inc.) for $1 \mathrm{~h}$, and 4,6-diamidino-2-pheylindole (DAPI) was used to stain the nucleus. All fluorescence signals were photographed with a fluorescence microscope.

Statistical analysis. The data in this study were calculated using GraphPad Prism (version 5.01 for Windows) and expressed as mean \pm standard deviation. Significance levels were assessed with Student's t-tests or one-way ANOVA followed by Bonferroni post-hoc comparison test (in cases of equal variances) or Welch and Brown-Forsythe tests (in cases of unequal variances). All statistical analyses were performed using SPSS software (version 20.0 for Windows; IBM Corp., Armonk, NY, USA). $\mathrm{P}<0.05$ was considered to indicate a statistically significant difference.

\section{Results}

Bufalin suppresses ACHN cell proliferation. To investigate the anti-cancer effects of bufalin on ACHN, the cells were treated with bufalin $(0,2.5,10,40$, and $80 \mathrm{nM})$ for 12,24 , 48, or 72 h. As shown in Fig. 1B, bufalin had a significant time-and dose-dependent inhibitory effect on ACHN cell proliferation. The IC50 values of bufalin for ACHN cells at $12,24,48$, and $72 \mathrm{~h}$ were $228.08 \pm 9.64,29.41 \pm 2.60,10.49 \pm 0.79$, and $6.7 \pm 0.97 \mathrm{nM}$, respectively. We then tested whether bufalin could attenuate the ACHN cell colony formation ability. As shown in Fig. $1 \mathrm{C}$ and D, the numbers and sizes of colonies formed were significantly reduced in a dose-dependent manner, from $233.00 \pm 12.12$ to $183.67 \pm 5.69,94.33 \pm 5.86$, and $65.33 \pm 4.51$ after treatment with bufalin (concentrations of 0,5 , 10 and $20 \mathrm{nM}$, respectively).

Bufalin induces G2/M phase arrest in ACHN cells by regulating the expression of p21, cyclin B1, and CDK1 in ACHN cells. To explore the potential mechanism of its anti-proliferative effect, we carried out cell cycle and apoptosis analyses. As shown in 
A

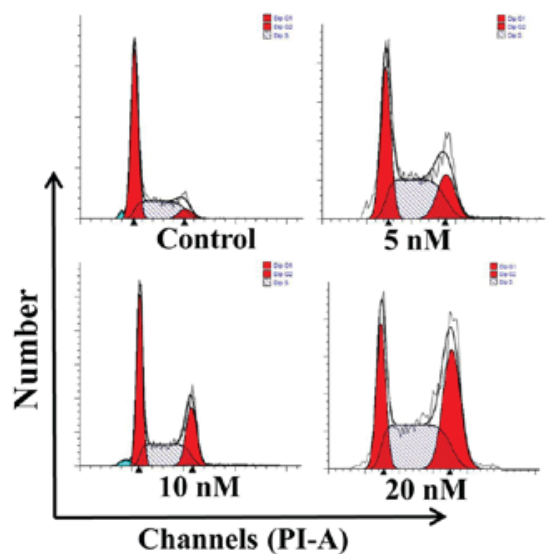

C
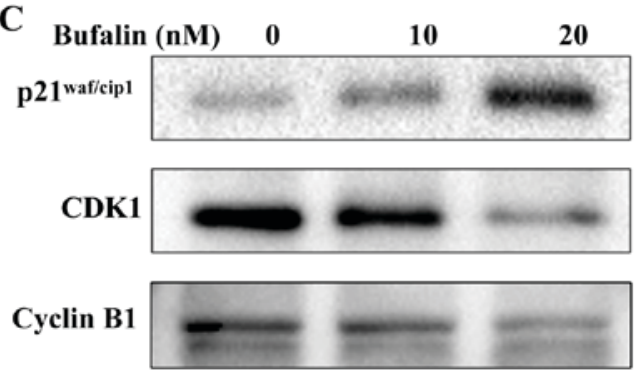

GAPDH

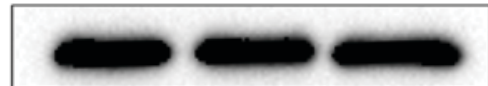

B

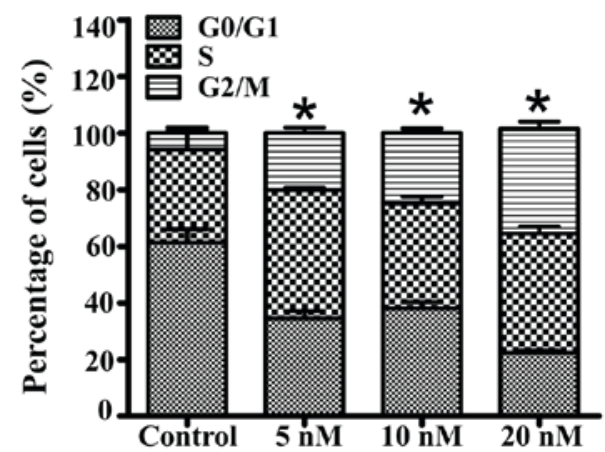

D

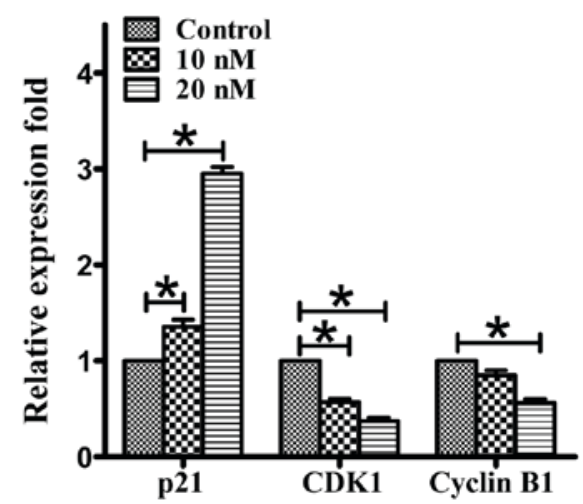

Figure 2. Bufalin induced cell cycle arrest in ACHN cells. (A) Percentage of cells in different phases was detected by flow cytometry. (B) Percentage of cells in the $\mathrm{G} 2 / \mathrm{M}$ phase significantly increased. Data are presented as mean $\pm \mathrm{SD}($ "P $<0.05)$. (C) Cycle-related protein expression was detected by western blot analysis after treatment with bufalin (concentrations of 0,10 , and $20 \mathrm{nM}$ ) for $24 \mathrm{~h}$. GAPDH was used as a loading control. (D) Bufalin treatment upregulated the expression of $\mathrm{p} 21$ and downregulated the expression of CDK1 and cyclin B1 in both the 10- and 20-nM treatment groups compared with the blank control The test was repeated three times, and the data are presented as mean $\pm \mathrm{SD}$. ${ }^{*} \mathrm{P}<0.05$. SD, standard deviation.

Fig. 2A and B, bufalin induced $\mathrm{G} 2 / \mathrm{M}$ phase arrest in ACHN cells. The percentage of ACHN cells in the G2/M phase increased from $7.86 \pm 0.96$ to $15.49 \pm 3.51,23.38 \pm 2.98$, and $37.07 \pm 7.05 \%$ after treatment with bufalin (concentrations of 0 , 5,10 , and $20 \mathrm{nM}$, respectively) for $24 \mathrm{~h}$. Under similar conditions, apoptotic cells were also assayed using the Annexin V-PI staining kit. Bufalin did not induce ACHN cell apoptosis at a dose of $20 \mathrm{nM}$ but induced apoptosis at a high dose of $80 \mathrm{nM}$. To unveil the mechanisms of the cycle arrest by bufalin, we analyzed cell cycle progression-related proteins by western blotting. As shown in Fig. $2 \mathrm{C}$ and D, p21 ${ }^{\text {waf/cipl }}$ expression was dose-dependently increased, and cyclin B1 and CDK1 expression was decreased in ACHN cell lines after bufalin treatment for $24 \mathrm{~h}$. GAPDH was used as a loading control.

Bufalin inhibits ACHN cell migration and invasion by regulating the expression of HIF-1 $\alpha, E$-cadherin, and $N$-cadherin in ACHN cells. We then assessed whether bufalin could inhibit ACHN cell migration and invasion. Wound-healing assays were performed to detect the cell migration speed. As shown in Fig. 3A and B, bufalin decreased the migration speed of ACHN cells in a dose-dependent manner. Our analysis also determined that bufalin significantly reduced ACHN cell invasion through Matrigel and migration through the membrane in the bottom chamber (Fig. 3C and D); these findings indicated that bufalin may inhibit ACHN cell migration and invasion. To determine the differences in epithelial-to-mesenchymal transition (EMT)-associated protein expression levels in ACHN cells before and after treatment with bufalin, further studies were performed using western blotting. Compared with the control group, after $24 \mathrm{~h}$ of treatment with bufalin, the expression level of $\mathrm{N}$-cadherin decreased, whereas that of E-cadherin increased in a dose-dependent manner in the bufalin-treatment group (Fig. 3E and F). The results of immunofluorescence staining confirmed the upregulation of E-cadherin in ACHN cells treated with bufalin (Fig. 4A). The results also showed that bufalin inhibited the expression of HIF-1 $\alpha$, a central player that accelerates invasion and metastasis in solid cancers.

Bufalin exerts its anti-tumor effects by regulating the expression of PI3K/Akt in ACHN cells. In this study, we demonstrated that bufalin exerts its anti-tumor effects by inducing ACHN cell cycle arrest and inhibiting metastasis. Furthermore, we determined that bufalin disrupted the PI3K/Akt signaling pathway. As shown in Fig. 4B and C, there were no significant changes in Akt protein expression. However, phospho-Akt (Ser473) and phospho-mTOR levels were reduced in both the 10- and 20-nM treatment groups compared with the blank control group; this finding implies that bufalin mediated anti-tumor responsevia phosphorylation. Correspondingly, PI3K protein expression decreased significantly in both the 10 - and 20-nM treatment groups compared with the blank control group. 

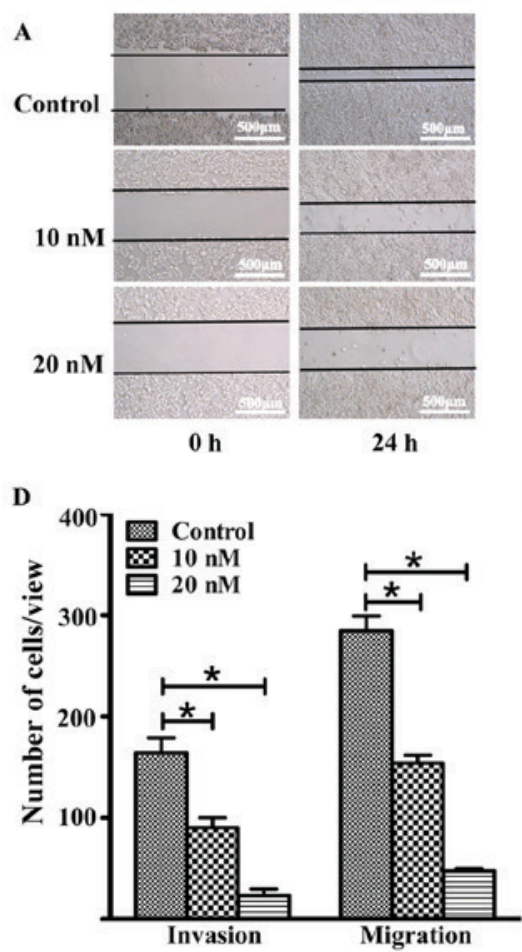

B
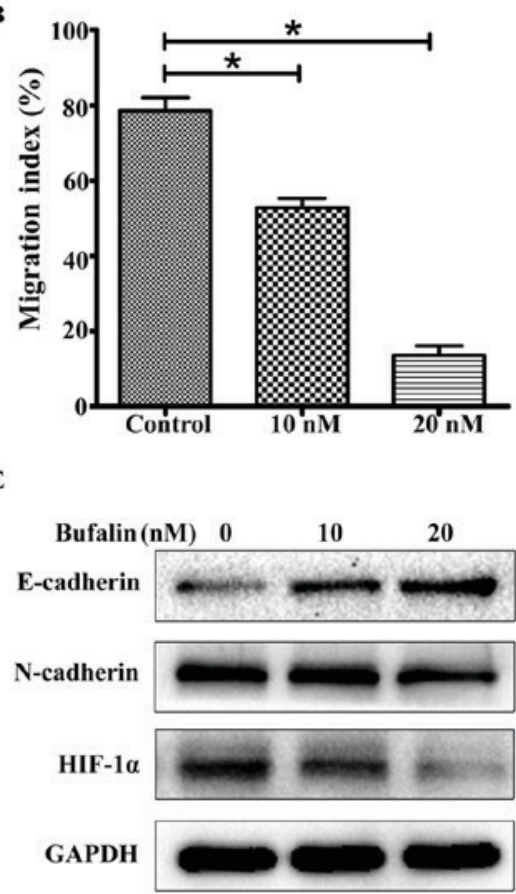

C
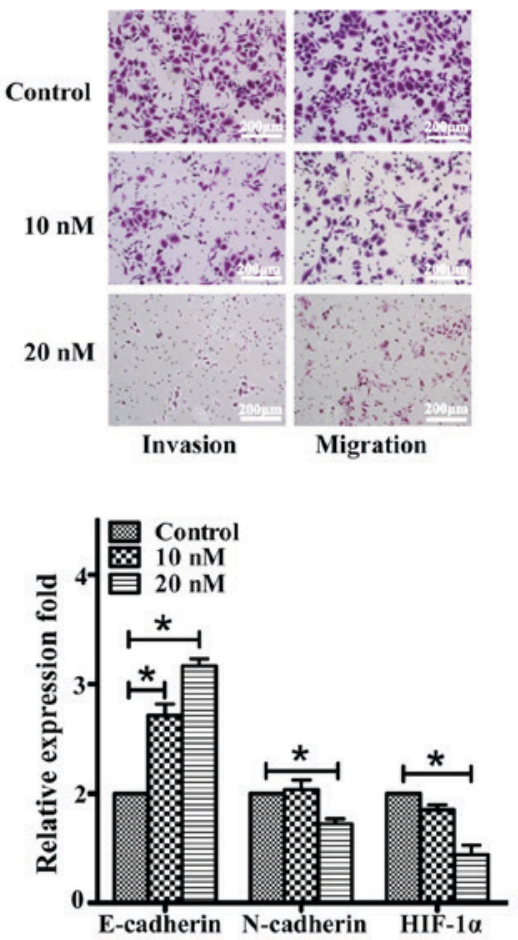

Figure 3. Bufalin suppressed renal carcinoma cell migration and invasion. (A) A wound-healing assay was performed to determine the migration ability of ACHN cells after treatment with various concentrations of bufalin for $24 \mathrm{~h}$ (magnification, x 50). (B) Bufalin significantly suppressed ACHN cell migration. Quantitative analysis of the migration speed was performed based on the migration index. Data are presented as mean $\pm \mathrm{SD}$. * $\mathrm{P}<0.05$. (C) Cell migration assay was performed using the Transwell assay after treatment with various concentration of bufalin for $12 \mathrm{~h}$ and then allowing invasion at $37^{\circ} \mathrm{C}$ for $24 \mathrm{~h}$. Invasion assays were performed similarly except that $50 \mu 1$ of Matrigel was added to the filter (magnification, x100). (D) The invaded cells were counted in four random fields after each treatment. The number of invaded cells significantly decreased after treatment with bufalin. Data are presented as mean \pm SD. ${ }^{*} \mathrm{P}<0.05$. (E) Metastasis-related protein expression was detected by Western blot analysis after treatment with bufalin (concentrations of 0 , 10 , and $20 \mathrm{nM}$ ) for 24 h. GAPDH was used as a loading control. (F) Bufalin treatment downregulated the expression of HIF-1 $\alpha$ and N-cadherin at $20 \mathrm{nM}$ only and upregulated the expression of E-cadherin in both the 10- and 20-nM treatment groups compared with the blank control. The test was repeated three times, and the data are presented as mean $\pm \mathrm{SD}$. ${ }^{*} \mathrm{P}<0.05$. SD, standard deviation.

A

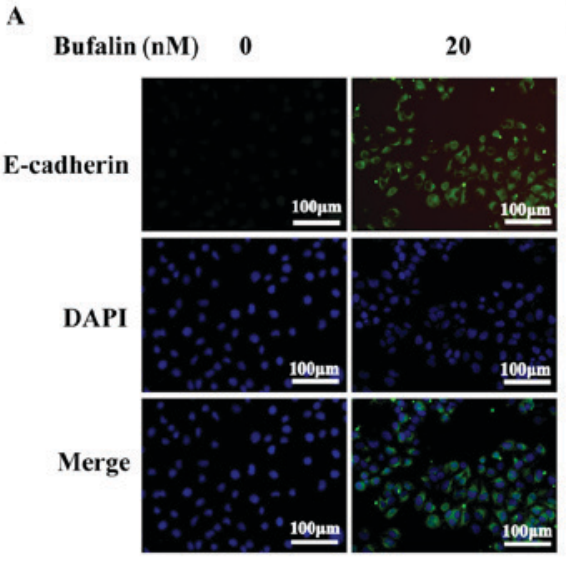

B

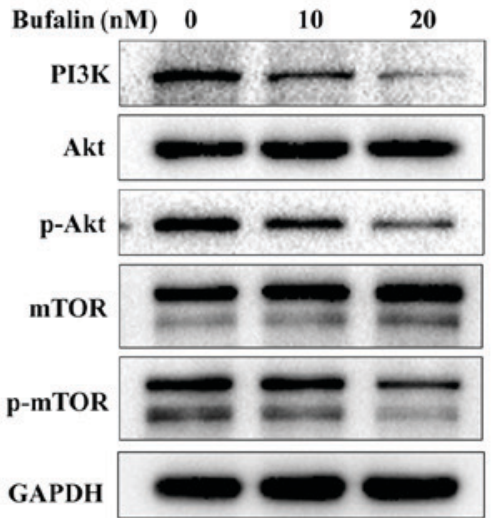

C

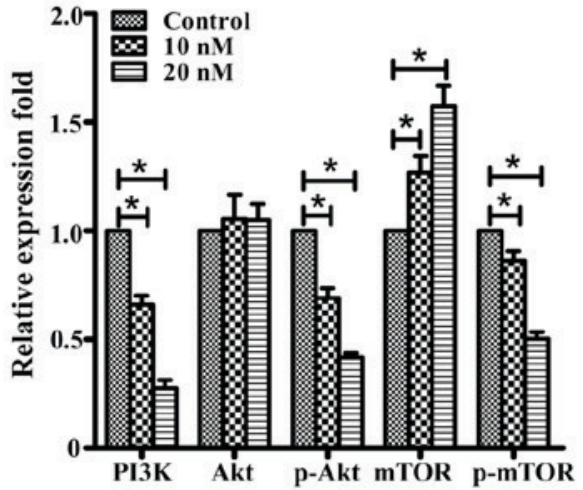

Figure 4. Bufalin suppressed the expression of p-Akt Ser473 in ACHN cells. (A) Two-color immunofluorescence analysis showing the expression of E-cadherin (green) and DAPI (blue) in ACHN cells treated with bufalin (concentrations of 0 or $20 \mathrm{nM}$ ) (magnification, x200). (B) PI3K/Akt signaling pathway-related protein expression was detected by Western blot analysis after treatment with bufalin (concentrations of 0,10 , and $20 \mathrm{nM}$ ) for $24 \mathrm{~h}$. GAPDH was considered as an internal standard. (C) Bufalin treatment downregulated the expression of p-Akt, PI3K, and p-mTOR in both the 10- and 20-nM treatment groups compared with the DMSO control. The test was repeated three times, and the data are presented as mean $\pm \mathrm{SD}$. ${ }^{\mathrm{P}}<0.05$. SD, standard deviation; PI3K, phosphoinositide 3-kinase; Akt, protein kinase B; mTOR, mammalian target of rapamycin.

\section{Discussion}

Although mRCC is one of the most treatment-resistant malignancies, there are new choices on the horizon $(4,22)$.
Currently, surgical management (metastasectomy and cytoreductive nephrectomy) remains an important component of the management of mRCC, and targeted therapies are beginning to demonstrate promising results $(5,23)$. In a large phase 3 trial 
of mRCC patients, Escudier et al (24) assessed the efficacy and safety of sorafenib and demonstrated that it significantly improved progression-free survival compared with a placebo. Thus, targeted therapeutic agents may play an increasingly important role in mRCC, and further studies are needed to understand the potential mechanisms.

The cytotoxic effect of bufalin has been demonstrated in various cancers. For example, the upregulation of p53 and induction of Fas-mediated cell apoptosis were shown to mediate the bufalin-induced death of prostate cancer cells (25). Bufalin was shown to induce cervical cell apoptosis and suppress the integrin $\alpha 2 / \beta 5 / F A K$-signaling pathway (21). However, the role of bufalin in RCC remains unclear. Our study is the first to demonstrate the suppression of p-Akt in bufalin-induced RCC cell cycle arrest and bufalin-reduced metastasis.

Our results showed that at a low dose of $5 \mathrm{nM}$, bufalin inhibited ACHN cell proliferation by blocking the cell cycle in the G2/M phase. Further study revealed that bufalin blocked the ACHN cell cycle via the upregulation of $\mathrm{p} 21^{\text {waf/cip1 }}$. However, bufalin did not induce apoptosis at an effective dose of $20 \mathrm{nM}$, but it induced cell apoptosis at a high dose of $80 \mathrm{nM}$. Interestingly, bufalin did not inhibit the proliferation of HK-2 cells, a normal renal proximal tubular cell line, at a high dose of $80 \mathrm{nM}$; this finding suggests that the effect of bufalin is specific to cancer cells.

To date, numerous studies have suggested that EMT is a key process in tumor metastasis. Hypoxia induces EMT via the HIF-dependent upregulation of transcription repressors of E-cadherin (12). Meanwhile, increasing evidence has addressed the molecular mechanisms underlying the reversal of EMT to exert anti-metastasis effects (26). Consistent with these studies, our results revealed an upregulation of the epithelial marker E-cadherin and a downregulation of the mesenchymal marker $\mathrm{N}$-cadherin, with reduced expression of HIF-1 $\alpha$ after treatment with bufalin. Thus, we tentatively suggest that bufalin inhibits RCC invasion and metastasis (Fig. 3) by regulating the HIF-1 $\alpha$ expression to reverse EMT.

Our study detected that bufalin treatment decreased the levels of p-Akt and its downstream signaling member, phospho-mTOR. By contrast, no significant changes in Akt protein expression were observed in any of the groups. The data indicated that bufalin exhibits significant anti-tumor activities, not only via reducing the expression of phospho-mTOR but also via the regulation of phospho-Akt. However, mutations in mTOR or PTEN and the activation of PI3K/Akt were observed in different cell lines after treatment with mTOR inhibitors (27). Thus, we believe that further studies on other types of RCC lines and in an in vivo metastatic model are required to better assess the therapeutic potential of bufalin.

In conclusion, to our knowledge, our study is the first to show that bufalin induces RCC ACHN cell cycle arrest and suppresses metastasis via disruption of the $\mathrm{PI} 3 \mathrm{~K} / \mathrm{Akt} / \mathrm{mTOR}$ signaling pathway. Our results indicate that bufalin is a potential therapeutic agent for RCC.

\section{Acknowledgements}

Not applicable.

\section{Funding}

This study was supported by scientific research grants from the Science and Technology Planning Project of the Guangdong Province (grant no. 2016A020215109) and The Ministry of Education, Culture, Sports, Science and Technology of Japan (grant no. 17K1113809).

\section{Availability of data and materials}

The datasets used and/or analyzed during the current study are available from the corresponding author on reasonable request.

\section{Authors' contributions}

$\mathrm{PH}$ and $\mathrm{CL}$ conceived and designed the experiments. JX, WL, LH and NX performed the experiments. WL, AX, BC, JX and MW analyzed the data. JX, NX and PH wrote the manuscript.

\section{Ethics approval and consent to participate}

Not applicable.

\section{Patient consent for publication}

Not applicable.

\section{Competing interests}

The authors declare that they have no competing interests.

\section{References}

1. Hirata H, Hinoda Y, Ueno K, Majid S, Saini S and Dahiya R: Role of secreted frizzled-related protein 3 in human renal cell carcinoma. Cancer Res 70: 1896-1905, 2010.

2. Tan X, Liu Y, Hou J and Cao G: Targeted therapies for renal cell carcinoma in Chinese patients: Focus on everolimus. Onco Targets Ther 8: 313-321, 2015.

3. Pei X, Li M, Zhan J, Yu Y, Wei X, Guan L, Aydin H, Elson P, Zhou M, He H and Zhang H: Enhanced IMP3 Expression Activates NF-KB pathway and promotes renal cell carcinoma progression. PLoS One 10: e0124338, 2015.

4. Sanchez-Gastaldo A, Kempf E, Gonzalez Del Alba A and Duran I: Systemic treatment of renal cell cancer: A comprehensive review. Cancer Treat Rev 60: 77-89, 2017.

5. Chandrasekar T, Klaassen Z, Goldberg H, Kulkarni GS, Hamilton RJ and Fleshner NE: Metastatic renal cell carcinoma: Patterns and predictors of metastases-A contemporary population-based series. Urol Oncol 35: 661.e7-661.e14, 2017.

6. Xiang RF, Wang Y, Zhang N, Xu WB, Cao Y, Tong J, Li JM, Wu YL and Yan H: MK2206 enhances the cytocidal effects of bufalin in multiple myeloma by inhibiting the AKT/mTOR pathway. Cell Death Dis 8: e2776, 2017.

7. Martini M, De Santis MC, Braccini L, Gulluni F and Hirsch E: PI3K/AKT signaling pathway and cancer: an updated review. Ann Med 46: 372-383, 2014.

8. Alessi DR, Andjelkovic M, Caudwell B, Cron P, Morrice N, Cohen $\mathrm{P}$ and Hemmings BA: Mechanism of activation of protein kinase B by insulin and IGF-1. EMBO J 15: 6541-6551, 1996.

9. Wang C, Wang Q, Li X, Jin Z, Xu P, Xu N, Xu A, Xu Y, Zheng S, Zheng J, et al: Lycorine induces apoptosis of bladder cancer T24 cells by inhibiting phospho-Akt and activating the intrinsic apoptotic cascade. Biochem Biophys Res Commun 483: 197-202, 2017.

10. Melnik BC: p53: Key conductor of all anti-acne therapies. J Transl Med 15: 195, 2017. 
11. Kitajima Y and Miyazaki K: The critical impact of HIF-1a on gastric cancer biology. Cancers (Basel) 5: 15-26, 2013.

12. Zong S, Li W, Li H, Han S, Liu S, Shi Q and Hou F: Identification of hypoxia-regulated angiogenic genes in colorectal cancer. Biochem Biophys Res Commun 493: 461-467, 2017.

13. Thomas JD, Zhang YJ, Wei YH, Cho JH, Morris LE, Wang HY and Zheng XF: Rab1A is an mTORC1 activator and a colorectal oncogene. Cancer Cell 26: 754-769, 2014.

14. Carew JS, Kelly KR and Nawrocki ST: Mechanisms of mTOR inhibitor resistance in cancer therapy. Target Oncol 6: 17-27, 2011.

15. Morishita S, Saito T, Mishima Y, Mizutani A, Hirai Y and Kawakami M: Pharmacological studies of Senso (Ch'an Su) containing drugs. Nihon Yakurigaku Zasshi 87: 361-378, 1986 (In Japanese).

16. Xu Y, Chen M, Jin XF, Qian C, Xu XM and Zhang X: Research progress of in vitro and in vivo anti-tumor effects and formulation of bufalin. Zhongguo Zhong Yao Za Zhi 39: 2829-2833, 2014 (In Chinese).

17. Tian X, Yin H, Zhang S, Luo Y, Xu K, Ma P, Sui C, Meng F, Liu Y, Jiang Y and Fang J: Bufalin loaded biotinylated chitosan nanoparticles: An efficient drug delivery system for targeted chemotherapy against breast carcinoma. Eur J Pharm Biopharm 87: 445-453, 2014

18. Zhao L, Liu S, Che X, Hou K, Ma Y, Li C, Wen T, Fan Y, $\mathrm{Hu}$ X, Liu Y and Qu X: Bufalin inhibits TGF- $\beta$-induced epithelial-to-mesenchymal transition and migration in human lung cancer A549 cells by downregulating TGF- $\beta$ receptors. Int J Mol Med 36: 645-652, 2015.

19. Wang H, Zhang C, Xu L, Zang K, Ning Z, Jiang F, Chi H, Zhu X and Meng Z: Bufalin suppresses hepatocellular carcinoma invasion and metastasis by targeting HIF- $1 \alpha$ via the PI3K/AKT/mTOR pathway. Oncotarget 7: 20193-20208, 2016.

20. Yuan XF, Tian HY, Li J, Jin L, Jiang ST, Liu KW, Luo C, Middleton DA, Esmann M, Ye WC and Jiang RW: Synthesis of bufalin derivatives with inhibitory activity against prostate cancer cells. Nat Prod Res 28: 843-847, 2014.
21. Liu F, Tong D, Li H, Liu M, Li J, Wang Z and Cheng X: Bufalin enhances antitumor effect of paclitaxel on cervical tumorigenesis via inhibiting the integrin $\alpha 2 / \beta 5 / F A K$ signaling pathway. Oncotarget 7: 8896-8907, 2016

22. Li X, Xu P, Wang C, Xu N, Xu A, Xu Y, Sadahira T, Araki M, Wada K, Matsuura E, et al: Synergistic effects of the immune checkpoint inhibitor CTLA-4 combined with the growth inhibitor lycorine in a mouse model of renal cell carcinoma. Oncotarget 8: 21177-21186, 2017.

23. Rodriguez-Vida A, Hutson TE, Bellmunt J and Strijbos MH: New treatment options for metastatic renal cell carcinoma. ESMO Open 2: e000185, 2017.

24. Escudier B, Eisen T, Stadler WM, Szczylik C, Oudard S, Siebels M, Negrier S, Chevreau C, Solska E, Desai AA, et al: Sorafenib in advanced clear-cell renal-cell carcinoma. N Engl J Med 356: 125-134, 2007.

25. Yu CH, Kan SF, Pu HF, Jea Chien E and Wang PS: Apoptotic signaling in bufalin- and cinobufagin-treated androgen-dependent and -independent human prostate cancer cells. Cancer Sci 99: 2467-2476, 2008.

26. Hu M, Peng S, He Y, Qin M, Cong X, Xing Y, Liu M and Yi Z: Lycorine is a novel inhibitor of the growth and metastasis of hormone-refractory prostate cancer. Oncotarget 6: 15348-15361, 2015.

27. Thaiwong T, Sirivisoot S, Takada M, Yuzbasiyan-Gurkan V and Kiupel M: Gain-of-function mutation in PTPN11 in histiocytic sarcomas of Bernese Mountain Dogs. Vet Comp Oncol 16: 220-228, 2018.

(i) (5) This work is licensed under a Creative Commons Attribution-NonCommercial-NoDerivatives 4.0 International (CC BY-NC-ND 4.0) License. 